\title{
DESIGN PARA TODOS: ESTUDOS SOBRE ABORDAGEM INCLUSIVA E ACESSIBILIDADE
}

Renato Fonseca Livramento da Silva, doutorando

Universidade Federal da Paraíba

fonsilva3@hotmail.com

Francisco Islard Rocha de Moura

Universidade Federal da Paraíba

islardrocha@hotmail.com

Resumo: Os princípios de acessibilidade e inclusão são fundamentais para participação das pessoas de forma igualitária na sociedade, são temas diretamente relacionados aos direitos humanos. Neste sentido, ações ligadas à promoção da igualdade, de modo a estruturar e promover uma sociedade para todos, considerando os princípios de acessibilidade, assume uma importância fundamental no sentido de se estabelecer estratégias para construção de uma sociedade mais justa, como colocam Simões e Bispo (2006, p. 61), ao defenderem que a "acessibilidade é parte integrante de uma política mais geral de sustentabilidade econômica, social e ambiental das cidades". Ao formular este pensamento, a partir de uma visão sistêmica, Simões e Bispo reforçam a complexidade do assunto e postulam que a harmonia entre os diversos aspectos relacionados à acessibilidade constitui ingrediente indispensável para sua implantação, que em geral se estabelece a partir de diálogo com cenários dinâmicos em constantes transformações. Dessa forma é possível afirmar, que nas ações de projeto sejam estas em qualquer escala, como na estruturação dos espaços urbanos privados, públicos ou dos artefatos que compõem e dialogam com estes espaços, prover o acesso e a participação ativa ao maior número de pessoas possível, de forma clara e segura, torna-se um fator primordial. No Brasil, a Norma NBR 9050/2004 (ABNT, 2004, p. 2) define acessibilidade como "a possibilidade e condição de alcance, percepção e entendimento para utilização com segurança e autonomia de edificações, espaço, mobiliário, equipamento urbano e elementos". Contudo, fica claro que não há cidadania efetiva se a acessibilidade é inexistente ou limitada. No âmbito projetual, os conceitos de Design inclusivo e Design universal, possuem como principal intuito evidenciar como essa abordagem é relevante para o processo de implantação dos critérios de acessibilidade nos ambientes, serviços e produtos e como são importantes nas interações que se estabelecem entre as pessoas e os espaços. Neste sentido, este projeto atua dentro do Departamento de Design da devida Instituição, localizada na cidade sede desta instituição, como grupo de estudos intitulado - Design para todos: estudos sobre abordagem inclusiva e acessibilidade, no intuito de pesquisar, organizar e 
difundir por meio de ações relacionadas aos temas Design inclusivo e Acessibilidade, pesquisas acadêmicas, projetos em disciplinas específicas do curso, desenvolvimento de trabalhos de conclusão de curso, projetos de pesquisa e extensão acadêmicas e apoio ao CIA - Comitê de Acessibilidade e Inclusão na referida instituição de ensino. Desta forma, pretende se colaborar para o desenvolvimento de uma cultura de inclusão nos campi da referida instituição. Acredita-se, portanto, que ações desta natureza ampliarão a capacidade dos pesquisadores para futuras ações no campo prático ligadas ao tema abordagem inclusiva do design e conceitos de acessibilidade.

Palavras-chave: Design, Design Inclusivo, Design Universal, Acessibilidade e Tecnologia Assistiva

\section{REFERÊNCIAS}

BRASIL. Ministério das Cidades. Secretaria Nacional de Transportes e da Mobilidade Urbana. Brasil Acessível: Programa brasileiro de acessibilidade urbana, Brasília, DF, 2006. 1 DVD. Inclui Caderno 1: Atendimento adequado às pessoas com deficiência e restrição de mobilidade, Caderno 2: Construindo a cidade acessível, Caderno 3: Implementação do decreto no. 5.296/04. 2006, Caderno 4: Implantação de políticas municipais de acessibilidade.

SIMÕES, Jorge Falcato. Design Universal: porquê? Design Inclusive, Cadernos de Design Anuário, Centro Português de Design, Lisboa, ano 9, n. 23/24, p. 82-83, 2001. 